\title{
Lewy body dementia versus Psychosis in Parkinson's disease A case of temporal evolution of psychosis and motor symptoms
}

\author{
Mădălina-Ionela Grosu, Alina Popa, Anina Rugină, \\ Marcel-Alexandru Găină, Roxana Chiriță
}

Mădălina-Ionela Grosu - M.D., Junior Psychiatrist, "Socola Institute of Psychiatry", Iași, Romania Alina Popa - M.D., Junior Psychiatrist, "Socola Institute of Psychiatry", Iași, Romania Anina Rugină - M.D., Junior Psychiatrist, "Socola Institute of Psychiatry", Iași, Romania Marcel-Alexandru Găină - M.D., Ph.D. student, "Grigore T. Popa" University of Medicine and Pharmacy, Junior Psychiatrist, "Socola Institute of Psychiatry", Iași, Romania

Roxana Chiriță - M.D., Ph.D. Professor, Department of Psychiatry "Grigore T. Popa" University of Medicine and Pharmacy, Senior Psychiatrist, "Socola Institute of Psychiatry", Iași, Romania.

\begin{abstract}
Lewy body dementia and Psychosis in Parkinson's disease have not only similar anatomic characteristics, both entities being categorized as alpha-synupleinopathies, but they also have in common clinical manifestations. Moreover, in recent years, the diagnostic criteria for both Lewy-body Dementia and Parkinson's-related Psychosis have been attempted and it has been noticed that the chronology of symptomatology is essential in differentiating them.
\end{abstract}

Although it is considered that the differential diagnosis between the two conditions is especially important for the field research, it is necessary to know and to distinguish them in order to establish an appropriate treatment. For example, as early as 2016, there are ongoing studies on the effectiveness of Pimavanserin in the treatment of Psychosis in Parkinson's disease. Additionally, diagnostic accuracy and certainty will increase significantly with the development of imaging techniques. Diagnostic certainty is currently possible only anatomopathologically.

The presented case reveals the need for an interdisciplinary collaboration - neurologist psychiatrist - radiologist, in order to establish a precise diagnosis which facilitates the therapeutic management of psychoproductive phenomenology (necessary to improve the quality of the patient's life). 


\section{Lewy Body Dementia, Psychosis in Parkinson's Disease, delusional disorder.}

\section{INTRODUCTION}

Lewy body dementia (DLP) is the second most common progressive neurodegenerative dementia after Alzheimer's disease, with a frequency of $1.7-30.5 \%$ of all dementia cases and $25 \%$ in patients with Parkinson's disease, the ratio of men to women being 1.5:1 (1).

The disease is defined by the diffuse involvement of cortical neurons that show inclusions such as Lewy bodies and by the absence or low number of neurofibrillary tangles and amyloid plaques (2).

Lewy bodies are neural inclusions consisting of abnormally phosphorylated neurofilamentary proteins aggregated with ubiquine and $\alpha$-synculin which can be identified by immunomarking. They are found in the substantia nigra in the brainstem causing dopaminergic deficiency; in the nucleus basalis of Meynert causing cholinergic deficiency; in the dorsal nucleus of the vagus, in the hippocampus regions $\mathrm{CA} 2$ and CA3 and in the transentorhinal cortex (3).

Clinically, Lewy body dementia shows an insidious onset and progressive evolution (4). The McKeith criteria supporting the diagnosis of Dementia with Lewy bodies have been revised in 2017 (5) and they focus on a clear differentiation between clinical elements and diagnostic biomarkers.

The presence of progressive cognitive decline with early changes in executive functions and attention, spontaneous elements of Parkinsonism ( axial and appendicular stiffness and parkinsonian tremors), complex, well-defined and recurrent visual hallucinations, REM sleep-associated behavior disorder (may be an early manifestation) as well as severe neuroleptic sensitivity generated by dopaminergic deficiency can be observed in Lewy body dementia (6).

Signs and symptoms that are frequently linked with the Lewy body dementia diagnosis are: hallucinations in different sensory modalities, tendency to develop paranoid ideation and, finally, systematized delusions; delusional recognitions, depression, repeated falls and syncopes, episodic confusion, severe autonomic dysfunction (orthostatic hypotension, urinary incontinence) (7).

The temporal sequence of symptoms is another diagnostic criterion, requiring a period of about one year between the appearance of dementia and the appearance of Parkinsonism (8). This temporal criterion is particularly important for the differentiation of Lewy bodies' dementia from Psychosis in Parkinson's Disease (PDP). Besides timeline, there are a few clinical and paraclinical differences that might be of use to physicians when confronting to an ambiguous case. (fig no 1$)$.

So that one may establish the diagnostic of Psychosis in Parkinson's disease, firstly, one must have a diagnosis of Parkinson's disease according to the clinical criteria established by the Movement Disorder Society (2015), and secondly, it is required the presence of at least one symptom of the following: delusions, hallucinations, a feeling of presence or delusional ideation, which must occur after the diagnosis of Parkinson's disease, most of the time, this happens more than 10 years apart (9). 
Bulletin of Integrative Psychiatry O New Series ODecember $2020 \bigcirc$ Year XXVI ONo. 4 (87)/99

\begin{tabular}{|c|c|c|}
\hline \multicolumn{3}{|c|}{ Fig. 1. The main differences between DLP and PDP } \\
\hline & Dementia with Lewy bodies & Psychosis in Parkinson's Disease \\
\hline $\begin{array}{l}\text { Timeline of } \\
\text { neuropsychiatric } \\
\text { symptoms versus } \\
\text { motor symptoms }\end{array}$ & $\begin{array}{l}\text { neuropsychiatric } \\
\text { symptoms occur before motor } \\
\text { symptoms }\end{array}$ & $\begin{array}{l}\text { neuropsychiatric symptoms occur after } \\
\text { motor symptoms }\end{array}$ \\
\hline $\begin{array}{l}\text { Parkinsonian } \\
\text { symptoms }\end{array}$ & 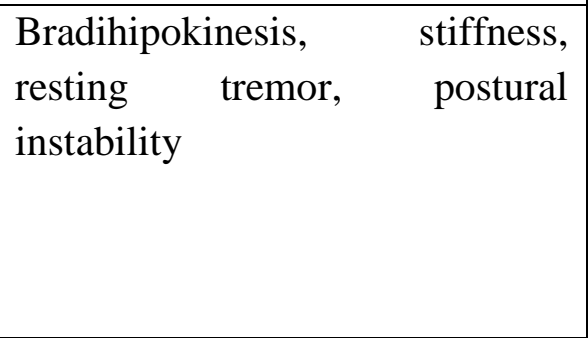 & $\begin{array}{l}\text { MDS } 2015 \text { clinical diagnostic criteria for } \\
\text { Parkinson's disease: parkinsonism } \\
\text { (bradihipokinesis +/- stiffness, resting } \\
\text { tremor) + evaluation of absolute } \\
\text { exclusion criteria, of red flags and of } \\
\text { support criteria (18) }\end{array}$ \\
\hline $\begin{array}{l}\text { neuropsychiatric } \\
\text { symptoms }\end{array}$ & $\begin{array}{l}\text { Very } \\
\text { hallucinations, especially visual, } \\
\text { but they may also be auditory, } \\
\text { tactile, olfactory or gustatory } \\
\text { hallucination (21) }\end{array}$ & $\begin{array}{l}\text { At least one of the following symptoms: } \\
\text { delusions, hallucinations (most } \\
\text { commonly visual, sometimes auditory, } \\
\text { rarely of another nature), delusional } \\
\text { disorder, a feeling of presence, for } \\
\text { example the vivid sensation that } \\
\text { somebody (distinct from oneself) is } \\
\text { present nearby. }\end{array}$ \\
\hline $\begin{array}{l}\text { Characteristics } \\
\text { neuropsychiatric } \\
\text { symptoms }\end{array}$ & fluctuating cognitive deficits & $\begin{array}{l}\text { neuropsychiatric symptoms are } \\
\text { continuous and persistent for at least one } \\
\text { month }\end{array}$ \\
\hline Sleep disorder & $\begin{array}{l}\text { REM sleep behavior disorder } \\
\text { may precede cognitive decline }\end{array}$ & $\begin{array}{l}\text { Insomnia, excessive daytime sleepiness, } \\
\text { restless legs syndrome, REM sleep } \\
\text { behavior disorder (19) }\end{array}$ \\
\hline $\begin{array}{l}\text { The response of } \\
\text { motor } \\
\text { symptomatology to } \\
\text { levo-dopa } \\
\text { medication }\end{array}$ & $\begin{array}{l}\text { In general, modest response to } \\
\text { dopaminergic medication, } \\
\text { sometimes at the risk of } \\
\text { worsening neuropsychiatric } \\
\text { symptomatology (20). }\end{array}$ & $\begin{array}{l}\text { Very good motor response to } \\
\text { dopaminergic medication, but at the risk } \\
\text { of triggering/ aggravating psychiatric } \\
\text { manifestations. }\end{array}$ \\
\hline
\end{tabular}

\section{CASE PRESENTATION}

66-year-old urban patient is brought by the family into psychiatric emergency, following an autolithic attempt by polydrug intoxication (she declares that she ingested 150 tablets of Zopiclona, Lorazepam and Nebivolol), presenting persecutory delusions (husband tries to makes me sick: every day he puts chemicals in my food, pours alcohol down my throat, violates me in my sleep), intrapsychic anxiety, negative mood, marked anxiety, emotional lability manifested by easy crying, feelings of helplessness and futility, hypnic disorders (mixed insomnia).

\section{MEDICAL HISTORY}

The patient is in evidence of the Institute of Psychiatry Socola Iasi with 38 previous hospitalizations, the first one at the age of 29, with the diagnosis of "Neurotic depression ". Over time, the patient was admitted for numerous autolithic attempts (the first one in 1993 by hanging, the second one in 1999 by ingestion of toxic substances, the third one in 2018 by ingestion of antiparkinsonian 


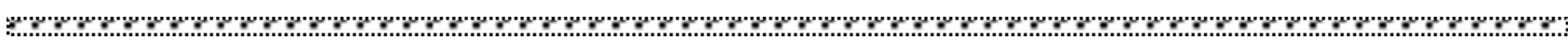
medication). These attempts occurred in chronic ischemic stroke, chronic kidney association with depressive-anxiety disease stage G3a.

syndrome, which increased after diagnosis in 1982, subsequently the clinical psychiatric picture aggravated in 2012 once the persecutory delusions, polymorphic delusions and hallucinations appeared.

The patient has been receiving treatment (since May 2012) with Olanzapine 15 $\mathrm{mg} /$ day; Mirtazapine $30 \mathrm{mg} /$ day and Bromazepam $1.5 \mathrm{mg}$ bid. However, because the patient did not tolerate antipsychotic medication, switching to Risperidone $5 \mathrm{ml} /$ day and Lorazepam 1mg, 1cpx2/day was performed; anticonvulsant treatment was continued.

In 2017, psychological examination reveals a decrease in cognitive function documented by the score of Mini mental State Examination (MMSE) of 23 points (mild cognitive impairment).

In 2018, the patient is diagnosed with Parkinson's disease and levo-dopa therapy is initiated, in the context of the following symptomatology: gait disorders, impairment of attention and memory, emotional lability, balance and postural disorders and upper limbs tremor which was more pronounced on the right side. It should also be noted that, at that time, the patient's medical letter did not mention the psychiatric history, so the diagnosis was most likely decided without knowing the patient's psychiatric history.

With the third autolytic attempt (2018), Olanzapina is replaced with Quetiapine 400mg/day.

The patient also presents numerous cardiovascular risk factors: arterial hypertension grade 2 additional high risk, ischemic cardiopathy, right external capsular

In addition, the patient is diagnosed with moderate-severe bilateral hearing loss.

Heredocolateral history of the patient, may reveal in this case, the presence of a genetic predisposition to neurodegenerative diseases. Thus, both the patient's father and a brother would have suffered from Parkinson's disease, and one of the daughters is also known to have mental disorders.

\section{PSYCHIATRIC EXAMINATION}

The patient had a cooperative, slightly suspicious and critical attitude towards the medical examiner. Manoeuvrability in conversation is objectified by elaborate responses, persevering on topics related to delusional thoughts of persecution. The patient's behavior is uninhibited. Body hygiene and clothing are suitable for the intrahospital environment. The voice, of medium tonality and increased intensity (the patient is diagnosed with bilateral hearing leave) reveals a bradilalic speech. There is also a slight latency in the responses, variable depending on the time of examination. The gaze is hypomobile, inexpressive, suspicious, initiates and maintains eye contact with the examiner about $80 \%$ of the interview time. Hypomobile mimics and reduced pantomime in amplitude and intensity are consistent with mood.

Multisensory hyperesthesia in the form of irritability and irascibility is present. Among the qualitative changes of perception is the presence of pathological visual illusions. The patient declares and gives details of one of her visual illusions: "my husband's pubic hair is knee-deep like a black ponytail", which appears in the delusional context of persecution being explained by the affective 
inversion to the husband. The patient also reports that when she is at home she smells of chlorine coming from the radiators and gasoline all over the house (olfactory hallucinations).

The memory retention is impaired, but it can observed a selective hypermnesia for events related to the delusional theme and for the negative events of the past (confrontational family situations). In addition, fluctuations of the cognitive status can be noticed, mostly regarding attention and reasoning ability.

There are some deficits regarding consistency in critical thinking (the patient makes abnormal, polarized associations to delusional themes). In addition, the patient shows a certain degree of false interpretation of reality, tangentiality and circumstantiality, offers details that are not necessary (she loses herself in details).

The patient also presents delusional thoughts namely: persecutory delusion "the husband pours alcohol down my throat", "the husband puts chemicals in my food", "the husband puts chlorine in the radiators", "the husband rapes me in my sleep". It can be noticed that all delusions are related to one person - the husband. When interviewed, the patient presented suicidal ideation and autolytic behavior "I can't live anymore because my husband hurts me every day".

The patient's mood is predominantly hypertimic negative pole with a low frustration tolerance. She has a slightly suspicious attitude. The dominant feelings are those of frustration and helplessness. Emotions are influenced by emotional ambivalence towards the husband and by a moderately emotional instability. The patient has no hobbies, interests or passions whereas motivation is governed by delusional ideas.
Moments of indecision and hesitation often occur during the psychiatric examination.

Volitionalally, the patient is characterized by a selective hyperbulia (in relation to the delusional thoughts) and hypobulia for daily activities. It is also detected a loss of appetite and a diminished personal performance. In regards to motor behavior, a modest bradykinesis is observed, the verbal activity is characterized by bradylalia while the intensity and tonality of the voice is increased. The patient reports sleep disorder such as mixed insomnia therefore sleep is drug-induced.

The psychological examination reveals a decrease in cognitive performance (objectified by MMSE score of 23 points) relevant in the context of memory and critical thinking deficits, as well as delusional disorder with impulsive and unstable behaviour based on organic substrate.

\section{PARACLINICAL INVESTIGATIONS}

Routine laboratory tests were carried out and they were inconclusive for any reversible cause of neurocognitive disorder or psychosis (e.g. in electrolyte disorders, uremia, various infectious syndromes, etc.). Apart from a mild normocytic normochromic anemia (HGB-10.3 g/Dl) and an inflammatory syndrome materialized by elevated inflammatory markers (VSH-33 $\mathrm{mm} / 1 \mathrm{~h}$, FIBRINOGEN-504 mg/dl).

The last imaging investigation performed, a native Cranio-Cerebral scan on 23.06.2020, reveals: discrete diffuse cerebral atrophy more obvious in fronto-temporal area, bilaterally symmetrical; sulcal and ventricular system enlargement.

Furthermore, a lacunar ischemic area of 6/4 $\mathrm{mm}$ is observed in the right external capsule and some discreet chronic lacunes in the pons. 


\section{POSITIVE DIAGNOSIS}

Dementia with Lewy bodies, according to the revised criteria of 2017, has as princeps criterion the existence of fluctuating cognitive deficits, which is not mandatory to be noticeable at the outset. Some of the most important diagnostic criteria are: impaired attention, alterations of executive function as well as impairments in visuoperceptual abilities. The patient obtained a score of 21 on the MMSE scale which translates in mild neurocognitive disorder.

Among the essential clinical manifestations, reported within the McKeith criteria, parkinsonian syndrome is pointed out which occurs simultaneously or after the installation of neurocognitive disorder. We must bear in mind that the diagnosis of Dementia with Lewy bodies can only be assumed if the neurocognitive disorder occurred before or up to 1 year after the onset of motor symptoms. Another crucial clinical criterion for diagnostic is the presence of psychoproductive symptoms such as welldefined, highly detailed visual hallucinations. The patient manifested both neurocognitive disorders and psychoproductive symptoms long before the appearance of extrapyramidal ones which were diagnosed in 2018 as Parkinson's disease. It should be noted that a number of patients have persisting neuropsychiatric symptoms even before impairment of cognitive function or parkinsonian syndrome (14).

Taking into account the above, the probable and possible Dementia with Lewy bodies diagnostic (according to McKeith 2017 criteria) should be considered.

\section{DIFFERENTIAL DIAGNOSIS}

Psychiatric disorders still represents a vast area and physicians are constantly challenged to improve patient outcomes. Thus, so that one may adopt the appropriate treatment plan one needs to know the accurate diagnosis. Given the known medical records of the patient, the following medical diagnoses were considered.

\section{DELUSIONAL DISORDER}

Delusional disorder is a medical condition that has its onset around the age of 35 and it is more prevalent in women. Being progressively aggravating tends to become a chronic illness. In addition, it is associated with suicidal behavior and delusion of persecution. On the other hand, it does not relate to depressive syndrome (may early and briefly occurs after the onset of psychotic symptoms) and also does not involve hallucinations. (15) The patient's psychiatric illness began with a depressive episode, hallucinations and delusional disorder have occurred afterwards.

\section{PSYCHOSIS IN PARKINSON'S DISEASE}

In most cases, psychosis is common in Parkinson's disease particularly in its later stages. At first, the patient is diagnosed with Parkinson's disease then, typically after a long-term evolution (10 years), neurocognitive disorder develop. The most characteristic symptoms of the disorder are: illusions, hallucinations, delusions, a feeling of presence. They are recurrent or persistent for at least a month and they consistently occur after the onset of extrapyramidal symptoms. Moreover, an important feature of the psychiatric symptoms of PBP is their progression over time. Hallucinations are the main characteristic of psychosis associated with Parkinson's disease, most often visual ones, occurring at the same time as auditory ones (as opposed to typical auditory hallucinations in schizophrenia). (16) Visual hallucinations govern the psychosis associated with Parkinson's disease (they arise 
r \%

about the same time as the auditory ones) while the dominant psychiatric symptom of the patient was delusional disorder. Therefore, the diagnosis Psychosis in Parkinson's disease was excluded.

\section{VASCULAR DEMENTIA}

The vascular dementia diagnosis is questionable although the patient has vascular risk factors. As long as psychiatric manifestations did not subsequently start after an acute cerebrovascular event and apart from extrapyramidal symptomatology, other neurological signs were not present, the vascular dementia diagnostic is excluded.

\section{OTHER NEURODEGENERATIVE DISORDERS THAT ASSOCIATE PARKINSONISM}

Progressive supranuclear palsy and corticobasal degeneration diagnostics are implausible as the patient does not experience other neurological symptoms and the imaging does not show specific changes.

Other primary psychiatric disorders concomitant with Parkinson's disease: schizophrenia, schizoaffective disorder, bipolar disorder, depression, substanceinduced mental impairment are scarcely possible given the patient's psychiatric history, symptomatology, clinical and paraclinical examinations.

\section{TREATMENT}

For patients with Lewy body dementia that show significant non-cognitive symptomatology with severe behavioral disorders, an acetylcholineesterase inhibitor is recommended. First-line treatment is represented by Rivastigmina (6 - $12 \mathrm{mg} /$ day).
If adverse effects or lack of efficacy, Donepezil (5-10 mg/day) is second line treatment (18).

In the 2002 McKeith randomized study, the effect of rivastigmine in improving cognitive function was demonstrated for patients with Lewy bodies' dementia being particularly noticeable in carrying out tasks that depend most on attention. Rivastigmine has also been noticed to improve memory mainly 12 weeks after starting treatment (19).

Treatment of REM sleep behavior disorder is represented by Clonazepam, being effective at doses low enough to be well tolerated. (20)

Regarding antipsychotic treatment it make sure precautions are taken. Haloperiodol increases the incidence of extrapyramidal symptoms and neuroleptic malignant syndrome. Even atypical antipsychotics, such as Olanzapine, appear to be poorly tolerated by patients with Lewy bodies dementia (the patient did not tolerate neither Risperidone nor Olanzapine treatment). A randomized, double-blind, placebo-controlled trial of Kurlan et al. showed that quetiapine is well tolerated in patients with DBD: there was no significant increase in adverse effects in the group treated with quetiapine (21).

Quetiapine, the antipsychotic administered to the patient, has a better safety profile than Clozapina (risk of agranulocytosis). Pimavanserin, a reverse agonist and 5HT2A receptor antagonist, without dopaminergic action, approved in 2016 for the treatment of psychosis in Parkinson's disease, is still under study for Lewy body dementia (22). Other antipsychotics are not recommended, as they can aggravate motor symptoms. 


\section{DISCUSSION}

The case presented, it questions the difficulty of establishing a correct diagnosis given a patient with various comorbidities (high blood pressure, Parkinson's disease etc.) and multiple hospitalizations for psychosis.

For an accurate diagnosis, a multidisciplinary approach is necessary. A good collaboration with the patient's attending neurologist and radiologist helps understand and determine whether the patient's psychiatric manifestations are of neurodegenerative origin (such as Parkinson's disease or Lewy bodies dementia), whether they are the psychic expression of an organic disorder (post-stroke sequel), or are a completely separate entity which coincidence with the already mentioned diseases of the patient. The hypothesis of drug-induced parkinsonian syndrome should also be excluded, given that the patient was on neuroleptic treatment when the diagnosis of Parkinson's disease was established. Psychosis induced by anti-parkinsonian medication should not be overlooked.

The patients presents a long history of depression which started 38 years ago at the age of 29), with a differing number of past suicide attempts, hallucinations and delusional disorder. Because of the multiple relapse of symptoms it can be assumed they were refractory to the implemented therapeutic strategies.

The delusional disorder (the patient's cardinal symptom) seems to be more common in Lewy bodies dementia than in psychosis in Parkinson's disease (23).

Considering the association of Parkinson's syndrome manifested by stiffness and hipokinesis, which appeared long after neuropsychic symptoms, we advocate for the diagnosis of probable Lewy bodies dementia, according to the McKeith criteria revised in 2017.

Unfortunately, with the current diagnostic methods available, a clear diagnosis of Parkinson's disease or Lewy bodies dementia cannot be assumed, the distinction between the two of them being purely conceptual. The two entities include common anatomological elements and they are categorized in the same nosological entity - alpha-siupleinopathy. However, at least for the time being, the distinction between this two pathologies is important for statistics and scientific research.

\section{ACKNOWLEDGEMENTS AND DISCLOSURES}

The authors declare that they have no potential conflicts of interest to disclose.

\section{REFERENCES}

1. American Psychiatric Association. Diagnostic and Statistical Manual of Mental Disorders DSM-5. 5th ed. Washington, DC: American Psychiatric Association; 2013

2. Wakabayashi K, Tanji K, Mori F et al. The Lewy body in Parkinson's disease: Molecules implicated in the formation and degradation of $\alpha$-synuclein aggregates. Neuropathology 2007; 27(5): 494-506.

3. Kosaka K. Lewy body disease and dementia with Lewy bodies. Proceedings of the Japan Academy, Series B Physical and Biological Sciences 2014; 90(8): 301-306.

4. Gaig C, Valldeoriola F, Gelpi E et al. Rapidly progressive diffuse Lewy body disease. Movement Disorders 2011; 26(7): $1316-1323$.

5. McKeith IG, Boeve BF, Dickson DW et al. Diagnosis and management of dementia with Lewy bodies. Fourth consensus report of the DLB Consortium. Neurology 2017; 89(1): 88 - 100.

6. Walker Z, Possin KL, Boeve BF et al. Lewy body dementias. Lancet 2015; 386(10004): 1683-1697.

7. Ochiai S, Sugawara H, Kajio Y et al. Delusional parasitosis in dementia with Lewy bodies: a case report. Annals of General Psychiatry 2019; 18: 29. 


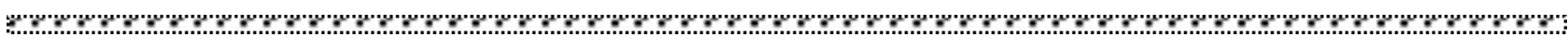

8. Savica R, Grossardt BR, Bower JH et al. Incidence of Dementia With Lewy Bodies and Parkinson Disease Dementia. JAMA Neurology 2013; 70(11): 1396 - 1402.

9. Ravina B, Marder K, Fernandez H. Diagnostic criteria for psychosis in Parkinson's disease: Report of an NINDS, NIMH Work Group. Movement Disorders 2007; 22(8): 1061 - 1068.

10. Schrempf W, Brandt MD, Storch A et al. Sleep disorders in Parkinson's disease. Journal of Parkinson's disease 2014; 4(2): $211-221$.

11. Salazar G, Cuello D, Fragoso M et al. Neuropsychiatric symptoms in Lewy body diffuse disease: A case report. Neurologia (English edition) 2011; 26(8): 499 - 502.

12. Goldman JG, Goetz CG, Brandabur M et al. Effects of dopaminergic medications on psychosis and motor function in dementia with Lewy bodies. Movement Disorders 2008; 23(15): 2248 - 2250.

13. Tousi B. Diagnosis and Management of Cognitive and Behavioral Changes in Dementia With Lewy Bodies. Current Treatment Options in Neurology 2017; 19(11) : 42.

14. Salazar G, Cuello D, Fragoso M et al. Neuropsychiatric symptoms in Lewy body diffuse disease: A case report. Neurologia (English edition) 2011; 26(8): 499 - 502.

15. Chirita R, Papari A, Chirita R. Tratat de psihiatrie. Constanta: Editura Andrei Saguna; 2009. Capitolul VIII: Alte tulburari psihotice; $345-347$.

16. Nadkarni S, Arnedo V, Devinski O. Psychosis in epilepsy patients. Epilepsia 2007; 48(9): 17-19.

17. Aarsland D, Ballard C, Larsen JP et al. A comparative study of psychiatric symptoms in dementia with Lewy bodies and Parkinson's disease with and without dementia. International Journal of Geriatric Psychiatry 2001; 16: 528 536.

18. McKeith IG, Del Ser T, Spano P et al. Efficacy of rivastigmine in dementia with Lewy bodies: a randomised, double-blind, placebo-controlled international study. Lancet 2000; 356(9247): 2031-2036.

19. Wesnes KA, McKeith IG, Ferrara R et al. Effects of Rivastigmine on Cognitive Function in Dementia with Lewy Bodies: A Randomised Placebo-Controlled International Study Using the Cognitive Drug Research Computerised Assessment System. Dementia and Geriatric Cognitive Disorders 2002; 13(3): 183-192.

20. Boot BP, McDade EM, McGinnis SM et al. Treatment of Dementia With Lewy Bodies. Current Treatment Options in Neurology 2013; 15(6): 738 - 764. Rice T, Dobry Y, Wang E et al. Cognitive effects of quetiapine in a patient with dementia with Lewy bodies. Psychogeriatrics 2013; 13(1): 52-57.

21. Kurlan R, Cummings J, Raman R et al. Quetiapine for agitation or psychosis inpatients with dementia and parkinsonism. Neurology 2007; 68: 1356-1363.

22. Ballard CG, Kreitzman DL, Isaacson S et al. Long-term Evaluation of Open-label Pimavanserin Safety and Tolerability in Parkinson's Disease Psychosis. Parkinsonism and Related Disorders 2020; 77: 100 - 106.

23. Postuma BR, Berg D, Stern M et al. MDS clinical diagnostic criteria for Parkinson's disease. Movement Disorders 2015; 30(12): $1591-1601$.

\section{Correspondence:}

Marcel-Alexandru Găină,

M.D., Ph.D. student, "Grigore T. Popa" University of Medicine and Pharmacy,Junior Psychiatrist, "Socola Institute of Psychiatry", Iași, Romania, alexandru-gaina@ d.umfiasi.ro

Submission: 18 may 2020

Acceptance: 5 aug 2020 